\title{
Contenidos en e-learning: El Rey sin corona (por ahora)
}

(Contents in e-learning: the king without a crown (at the moment)

JAVIER MARTíneZ ALDANONDO

Director de Proyectos

Talentus ,Servicios Innovadores en Aprendizaje http:www.talentus.cl Corporación de Investigación Tecnológica - Intec http://www.intec.cl

RESUMEN: ¿Como aprendemos realmente? ¿Qué papel puede jugar la tecnología para un mejor aprendizaje? ¿Por qué existe una tan alta tasa de abandonos entre los alumnos de los cursos de e-learning? ¿Como podemos convertir una experiencia de recepción pasiva de información en una experiencia activa de construcción de conocimiento.

e-learning - tecnología - tasas de abandono - constructivismo

ABSTRACT: How do we really learn? What is the role that technology can play in order to obtain a better learning? Why is so high the drop-out rate among participants in e-learning courses? How can we transform a passive reception of information into an experience of active construction of knowledge?

e-learning - tecnología - drop-out rates - constructivism 
Érase una vez (principios de los años 80) un joven (yo) que pensó que había llegado el momento de aprender a conducir. Y para lograrlo, la opción más evidente era la de matricularse en una autoescuela. Existía, además otra opción que consistía en sentarse a los mandos de un coche (el de mi padre) junto con alguien experimentado (mi padre) que me ayudase a aprender.

Como la segunda opción era más sencilla (y económica) comencé por pilotar el coche de mi padre por algunos lugares poco concurridos de San Sebastián, abusando de su paciencia y tratando de seguir sus consejos cada vez que no hacía las cosas de la mejor manera. Con el tiempo, no me quedó otra alternativa que matricularme en la autoescuela, estudiar el código de circulación y realizar multitud de tests de respuesta múltiple e incluso pagar por el mínimo de clases prácticas obligatorias. Como colofón de la historia y como todos hemos hecho, tuve que superar el examen teórico y el examen práctico (recuerdo que era uno de los pocos días que he visto nevar en San Sebastián y podía sentir en el cogote el aliento del parco e inexpresivo examinador). Resultado: Casi dos décadas después sigo conduciendo normalmente aunque tengo serias dudas sobre si sería capaz de aprobar el examen teórico.

Supongo que habrá personas que se preguntarán porqué he escogido este ejemplo para tratar el tema de los contenidos de e-learning. Como veremos, hay múltiples aspectos comunes:

Dl aprendizaje tuvo lugar fuera de las aulas: reflejos, educación, prudencia, averías, atascos, accidentes ...

D La motivación

D El aprendizaje en el momento en que se necesita

D Aprender haciendo

Da importancia de cometer errores

D El razonamiento

La posibilidad de tener expertos a quien acudir en el momento de cometer los errores

D El papel de las emociones

Sin embargo, la manera en que aprendemos a conducir no es ni mucho menos un ejemplo habitual sobre la forma en que nos enseñan el resto de habilidades y conocimientos necesarios para trabajar y vivir en nuestra sociedad.

No tengo ninguna intención de añadir otra definición de e-learning a la larga lista que circula hoy en día entre nosotros. También quiero adelantar que estamos en los albores de algo que presumiblemente va a tener un impacto enorme en la manera en aprenderemos a partir de ahora, al igual que los ordenadores han cambiado sin remedio nuestra forma de trabajar. Sin embargo, el principal me- 
dio de producción en la aldea global sigue siendo el cerebro humano. Sabemos que los contenidos no tienen un poder mágico para convertir a un alumno en un experto. Aprender es una tarea compleja, es una habilidad en si misma, que requiere tiempo y diseñar unos buenos contenidos también. Y como todo en Internet, los alumnos están siempre a un solo click de ratón de abandonar el curso.

Como punto de partida me gustaría señalar cuáles son las dos preguntas que nos debemos hacer a la hora de valorar un contenido de e-learning:

1. ¿Cuánto se parece al trabajo para el que intentamos formar al alumno? Por ejemplo, si es un curso de Negociación, ¿el alumno negocia? ¿Se enfrenta a diferentes situaciones, personalidades, problemas?

2. ¿Qué sabe HACER el alumno cuando finaliza que antes no sabía? El alumno, ¿sabe negociar? cuando llegue a su trabajo, ¿se darán casos donde piense «esto lo hice ayer en el curso, sé que me equivoqué pero también sé cómo lo resolví y por tanto puedo aplicarlo»?

Si somos mínimamente críticos, nos daremos cuenta de que pocos, muy pocos contenidos -de e-learning o no- superan esta primera prueba.

Para empezar a hablar de contenidos debemos tener en cuenta tres aspectos que por regla general pasan inadvertidos y que sin embargo son la clave sobre la que se asienta todo lo demás: CÓMO aprenden las personas y en función de esto, CÓMO enseñamos y QUÉ enseñamos.

Para analizarlo -y aunque pensemos que el e-learning es el futuro que nos espera- tan solo tenemos que retroceder unos cuantos siglos: Sócrates predicaba que el conocimiento estaba dentro y no fuera de las personas y trataba de ayudarlas a razonar por sí mismas. Aristóteles sentenció en su momento «Lo que tenemos que aprender, lo aprendemos haciendo». Los romanos también entendieron que Educare consiste en extraer lo mejor de uno mismo. Plutarco decía «El cerebro no es un vaso que hay que llenar sino una chispa que hay que encender». Incluso Galileo sentenció «No se puede enseñar nada a ningún hombre, simplemente podemos ayudarle a descubrirlo por sí mismo.» ¿Y qué hacemos nosotros? Tratamos de llenar las cabezas de los alumnos con ingentes cantidades de datos, les hacemos un examen y si responden lo que el profesor ha dicho, aprueban y obtienen un título. Pero el mejor maestro no es el que da la respuesta correcta sino el que ayuda a encontrarla por uno mismo. Medimos los cursos por los «kilos» de contenidos, por las horas de clase. La capacidad de procesar información de los humanos es finita. Einstein dijo: «No necesito saberlo todo. Tan solo necesito saber donde encontrar lo que me haga falta, cuando lo necesite».

Pero la realidad, y todos los que estudiamos una carrera universitaria lo hemos podido comprobar en nuestras carnes, es muy diferente. En la vida no hay respuestas correctas ni nos hacen exámenes escritos a final de mes en el trabajo. 
La vida es mucho más compleja que todo eso. Como mucho hay cosas que funcionan y cosas que no. Lo más importante en una empresa no son las personas, ni siquiera el conocimiento de esas personas. Lo más importante es su EXPERIENCIA, lo que SABEN HACER. Es por esa razón por la que les contratan, por la que aportan valor y por la que les pagan. Si nos paramos a pensar, la mayor parte de las cosas que hacemos en el trabajo no las hemos aprendido ni en el colegio ni en la universidad. Las hemos aprendido a lo largo de muchos años de trabajo y esfuerzo, de cometer errores, aprender de ellos y acumular una valiosísima experiencia. Y cuanta mas experiencia tenemos en un trabajo, mejor lo hacemos. Yo no aprendí a conducir en la autoescuela, aprendí a lo largo de muchas horas sentado al volante haciendo kilómetros y viviendo situaciones diferentes.

Esto conduce a la primera afirmación sobre CÓMO APRENDEN LAS PERSONAS. Aprendemos haciendo y no escuchando. El modelo «Yo sé, tú no sabes, yo te cuento» no es real. Cuando una persona se hace una pregunta quiere decir que está pensando, explorando, buscando explicaciones, soluciones. Sólo entonces puedo estar seguro de que empieza a aprender. ¿Qué oportunidades damos en los cursos de pensar, investigar, experimentar, preguntar?.

Para aprender, este suele ser el proceso que seguimos inconscientemente:

Dijarnos un Objetivo (por ejemplo, ir de vacaciones a Australia)

D Actuar en consecuencia (reservar avión, alojamiento, buscar información del país, etc).

Ds probable que vayamos al aeropuerto y que las cosas no sucedan como esperábamos porque, por ejemplo, nos encontremos un problema de Overbooking que nos deja en tierra hasta el día siguiente.

Deflexionamos, buscamos una explicación (hay que confirmar el vuelo con 48 horas de antelación) y la almacenamos en la memoria. APRENDEMOS. La siguiente vez que planifiquemos unas vacaciones, sabremos que tenemos que confirmar el vuelo antes de ir al aeropuerto.

En el fondo, un experto no es más que una persona que acumula gran número de casos, ha practicado tantas veces unas determinadas tareas que ha terminado por dominarlas perfectamente. Ha creado respuestas automáticas a todos esos casos, ha acumulado la experiencia de cómo resolverlos de manera que sabe responder a ellos casi sin pensar. La única diferencia con los demás es que se ha entrenado con esmero para solucionar todos esos casos. Pero no olvidemos que al comienzo era igual que los demás, empezó de cero.

En la oficina no nos pasamos las horas sentados en una silla escuchando a alguien, nos pasamos las horas haciendo cosas continuamente. Si fuese tan sencillo, bastaría con escuchar a los mejores expertos en cada materia para convertirnos en expertos como ellos y de esta manera acabaría el fracaso escolar y en 
Contenidos en e-learning: El Rey sin corona (por ahora)

gran medida el negocio de la formación sería diferente. Los problemas no se pueden comprender intelectualmente, hay que vivirlos. ¿Alguien piensa que podemos modificar el comportamiento de las personas, cambiar su manera de hacer las cosas para que las hagan mejor por el mero hecho de sentarlas en un aula o ponerles unos textos en una pantalla y unos ejercicios?

Si lo que se aprende no procede del descubrimiento personal, de una experiencia o de un caso concreto, no se recuerda ni se aprende. ¿Quién de nosotros sería capaz hoy de aprobar un examen de cualquiera de las asignaturas de la carrera? Posiblemente casi nadie. El problema no es que se nos haya olvidado, el problema es que nunca lo aprendimos. Lo único que hicimos fue memorizar una serie de datos para una fecha determinada. A partir de aquí el cerebro, que tiene una enorme facilidad para eliminar lo que no necesita o utiliza, sustituyó aquello por otras informaciones y lo borró. De hecho el conocimiento real es inconsciente. Para tratar de explicar y formalizar lo que realmente sabemos hacer, tenemos que pararnos a pensar un buen rato y nos costará trabajo tratar de enunciarlo claramente.

Por ejemplo, para aprender a conducir, yo tuve que superar 4 fases:

1. No sé que no sé. Con 12 años, ni sabía conducir ni sabía que hubiese que saber conducir porque no era un tema que me preocupase lo más mínimo.

2. Sé que no sé. Con 18 años me di cuenta que conducir era algo útil y yo no sabía hacerlo.

3. Sé que sé. Cuando me bajé del coche aquel día de noviembre en que nevaba, era consciente de que ya sabía conducir aunque tenía que pensar cuidadosamente casi cada paso que daba.

4. No sé que sé. Hoy cuando cojo el coche, ni siquiera tengo que pensar en lo que hago. Ponerme el cinturón, arrancar el coche, soltar el freno, pisar el embrague, meter marcha atrás... se ha convertido en algo inconsciente.

Aquí podemos introducir uno de los aspectos relevantes de los contenidos de e-learning. La motivación. Yo aprendí a conducir cuando me di cuenta que para no depender del transporte público, de terceras personas (casi siempre mis padres) o de otras limitaciones, la mejor solución era aprender a conducir. La motivación no existía a los 12 años pero sí a los 18 de la misma manera que hace 12 meses poca gente estaba motivada para aprender a pensar en el Euro como moneda. Sin embargo, la motivación es algo básicamente interno, no puede ser impuesto, y una persona motivada es capaz de aprender de un trozo de periódico viejo mientras una persona que no lo está no aprenderá aunque le paguemos un MBA en Harvard.

Ahora bien, todas las personas nos movemos por objetivos, cosas o situaciones que nos interesan y por las que estamos dispuestos a actuar para alcanzarlas 
porque nos producen sensaciones placenteras. Cuando tienes un objetivo, tienes interés en aprender para alcanzarlo. Este es un elemento fundamental porque el alumno aprende cuando él quiere y no cuando lo decide el profesor. No podemos obligarle a aprender lo que nosotros sabemos sin que le hayamos despertado un interés previo. Tampoco podemos enseñarle lo que hemos decidido que queremos que sepa y menos todavía si es capaz de darse cuenta que seguramente no podrá aplicar o transferir a su trabajo lo que le estamos contando. El protagonista ya no va a ser el profesor que deja de ser el poseedor de los conocimientos y la autoridad que decide sobre el futuro del alumno. Pero si somos capaces de alinearnos con sus objetivos, si somos capaces de entender que es lo que le mueve, lo que le motiva, lo que le gusta, entonces tenemos una ocasión incomparable para diseñar unos contenidos que resulten atractivos y donde sea el protagonista de una historia donde deberá jugar un papel activo, un rol principal para construir su propio conocimiento.

Y es aquí donde generalmente se está desperdiciando una gran oportunidad. ¿Cómo podemos esperar que los alumnos dediquen su tiempo («anytime» suele ser su tiempo libre) y su propio espacio («anywhere» acaba siendo su propia casa) para leer manuales aburridos convertidos a HTML en una pantalla y hacer tests de autoevaluación? Al menos en el aula pueden charlar con sus compañeros cuando se aburren. El ordenador es un «doing device», un aparato para hacer cosas y no para pasar páginas ni para escuchar pasivamente. Para eso ya está la televisión.Pulsar iconos no es sinónimo de Interactivo. E-learning no significa leer en la pantalla del ordenador lo que antes leíamos en un papel. Ni multimedia (animaciones preciosas, sonidos, imágenes, videos espectaculares) es sinónimo de aprendizaje. La razón por la que muy poca gente es capaz de disfrutar haciendo un curso vía e-learning es porque quien lo ha diseñado, lo ha hecho pensando en sí mismo, en lo que sabe y en lo que cree que los demás deben saber. Sin embargo vivimos una era donde es el cliente el que juzga los productos y no al revés, donde tenemos que hacer las cosas con el cliente como punto de referencia, pensando en lo que le gusta, lo que disfruta y lo que necesita. Pero eso significa realizar un trabajo bastante más complejo.

Veamos un par de ejemplos: Posiblemente para un niño aprenderse de memoria las capitales de las provincias españolas no sea un plato de muy buen gusto. Sin embargo si diseñamos un contenido donde el niño forma parte de un equipo de fútbol o de un grupo musical que cada semana tiene que jugar o actuar en una ciudad distinta, es altamente posible que en el propósito de alcanzar el objetivo que le motiva (planificar cada viaje, jugar o actuar en cada ciudad), el niño aprenderá lo que queremos y lo hará divirtiéndose y sin darse cuenta.

Segundo ejemplo, un curso de Macroeconomía y lo elijo por que lo encuentro especialmente árido. Todos los modelos que se manejan hoy en día se parecen como gotas de agua a la hora de impartir un curso de Macroeconomía, da lo mismo 
que sea presencial o no. Monólogo del Profesor o experto cualificado, durante muchas horas y tal vez algún tipo de evaluación para comprobar si los alumnos han entendido los conceptos. ¿Resultado? Curso en principio poco atractivo, con un enorme caudal de contenido teórico y poquísima interacción y aprendizaje real.

¿Podemos pedir al alumno que se motive? Difícilmente. ¿Que participe -y sobre todo- que cuando acabe tenga los conocimientos suficientes para ejercer un trabajo en esa área? Es mucho pedir. El propio alumno tiene sus dudas sobre si «sabe que sabe» ¿Seré capaz de HACER lo que me han dicho que hay que hacer en mi trabajo diario?. Sin embargo, el problema no radica en el alumno, ni siquiera en la materia. Radica en el método.

¿Hay algo que podamos hacer? El ser humano es por naturaleza curioso, le gusta jugar (al fútbol, a las cartas, a juegos de rol o a hacer crucigramas). Planteemos las cosas al revés. Lo lógico es que si alguien quiere o debe hacer un curso de Macroeconomía es porque trabaja o quiere trabajar en algún puesto donde pueda aplicar esos conocimientos. Entonces, construyamos una historia que recree, lo mejor posible, una situación real de trabajo donde tenga que poner en práctica sus conocimientos. Tenemos que crear un escenario donde situar al alumno, asignándole un papel y un objetivo a cumplir, una meta. Propongámosle por ejemplo, «Vas a trabajar en el equipo de asesores del presidente de los USA, se desata una crisis de suministro de petróleo y tu tarea consistirá en asesorarle sobre las diferentes medidas que habrá que tomar para solucionarlo».

De entrada ya le estamos planteando un reto y la aplastante mayoría de los seres humanos reaccionan positivamente ante estos estímulos sobre todo cuando identifican que les va a reportar beneficios directos sobre su desempeño profesional. No le aburrimos con introducciones sobre el curso, sobre para qué le servirá. Tenemos que captar su atención e interesarlo desde el comienzo. Que adopte una actitud proactiva, que "haga cosas». A partir de aquí, el alumno va a ser quien tendrá las claves para desenvolverse en un entorno donde va a encontrar todos los elementos que necesite, en forma de información, videos de expertos, historias reales sobre casos similares, instrumentos de trabajo, para llevar adelante su tarea y «hacer cosas» (un informe al presidente, defender el informe en una rueda de prensa, etc.). Pero tendrá que hacerlo él, con su cerebro y su razonamiento. Y sobre todo fracasando y razonando sobre los motivos de su fracaso hasta dar con la solución su error. No hay mejor tutor que uno mismo cuando está cautivado por una actividad que le fascina.

\section{CÓMO ENSEÑAMOS}

Tenemos que reconocer que la educación ha evolucionado muy poco a lo largo del tiempo. Si pudiéramos trasladar en el tiempo a un cirujano de hace 400 
añosa un quirófano de hoy, posiblemente entraría en shock por la diferencia de escenarios y su incapacidad para entender la situación. Sin embargo, si hacemos el mismo experimento con un profesor, es casi seguro que en 5 minutos podría tomar el mando y seguiría la clase con total normalidad (los pupitres de la famosa aula de Fray Luis de León no son muy diferentes de los que yo utilicé). La tónica habitual sigue siendo pizarra y borrador y esto significa que el profesor hace el 95\% de trabajo. Habla, lee, explica, escribe, dicta, pregunta, etc. Pero lo curioso es que quien debería hacer el 95\% del trabajo debería ser el alumno que es quien debe aprender. ¿Alguien se imagina a un padre enseñando a montar en bici a su hijo y empleando el 95\% del tiempo pedaleando sentado sobre la bici mientras su hijo le escucha? ¿O aprender a cocinar viendo a Arguiñano en la tele? Además, no siempre el que enseña es el profesor ni el que aprende es el alumno.

En el caso del e-learning, estamos reproduciendo prácticamente el mismo modelo, dejando nulo espacio al alumno para que reflexione, tome decisiones, investigue, se cuestione y tenga dudas. Todo lo que le pedimos es que avance páginas, lea y escuche y al final haga unos cuantos tests.

Para aprender, el protagonista debe ser el alumno que tiene que hacer cosas y no escuchar pasivamente como se las cuenta otra persona. Nadie aprende a negociar si no es negociando y practicando mil veces hasta perfeccionar la habilidad que acaba siendo automática e inconsciente. Y para ello tiene que experimentar, cometer errores, reflexionar, buscar explicaciones, recibir el consejo de quien sabe, intentarlo de nuevo, es decir siendo Proactivo. La memoria y el aprendizaje van íntimamente ligados a las emociones. Y no parece muy emocionante ni impactante saber que durante un curso (o una carrera) tu papel es el de sentarte en un aula a escuchar y coger apuntes. Si cada vez las personas van a tener mas autonomía y mas poder de decisión, habrá que prepararles para ello y no tan solo para aplicar las reglas como si fuesen robots.

\section{QUÉ ENSEÑAMOS}

Según lo que las propias empresas solicitan, este sería el retrato robot del perfil del universitario recién licenciado que necesitan (no es exhaustivo ni mucho menos):

D Capacidad de escribir y redactar correctamente y de forma estructurada.

D Hablar en publico y hacer presentaciones verbales y escritas.

D Capacidad de análisis.

D Razonamiento y resolución de problemas. Negociación.

D Trabajo en Equipo. 
Dspíritu Emprendedor.

Dreatividad e Innovación.

D Comunicación.

D Inteligencia emocional.

D Capacidad para aprender y desaprender.

Por desgracia, esto no es lo que se aprende en la universidad (ni casi en ninguna parte, lo aprendemos trabajando y practicando). La universidad fabrica académicos, profesores deprimero de carrera pero no profesionales. Entre otras muchas cosas porque quienes suelen impartir las clases tampoco son profesionales sino académicos. Es casi aquello de cómo me va a dar un sacerdote lecciones sobre el matrimonio (a no ser que considerásemos que estuviese casado con Dios). Esto es tan evidente, que las empresas están creando sus propias Universidades Corporativas para tratar de corregir este problema. Existen ya varios cientos de universidades corporativas censadas en Estados Unidos, fenómeno que comienza a extenderse en nuestro país. Lo malo es que luego reproducen, con los mismos errores, el mismo modelo de formación que las otras universidades.

Todas aquellas habilidades por las que realmente somos valorados para acceder a un trabajo prácticamente no aparecen por ningún sitio en la universidad. Recibimos clases de Latín, de Álgebra, de Trigonometría y de muchas cosas más que jamás utilizamos ni recordamos y sin embargo nunca aprendemos sobre Salud y Nutrición o a Aprender a Convivir con una pareja durante muchos años.

En Estados Unidos existen algunas iniciativas donde las propias empresas están preparando esos retratos robot que recogen las capacidades básicas que necesitan para sus nuevos empleados y se está negociando con algunas universidades para empezar a crear curriculums universitarios adaptados a estas necesidades.

\section{ASPECTOS CLAVE PARA DISEÑAR CONTENIDOS DE E-LEARNING}

Vamos a tomar como base el ejemplo que nos ha servido de guía hasta este momento que es el de Aprender a Conducir.

Aprender Haciendo: Parece obvio pensar que aprender a conducir es una actividad de «Hacer». El aprendizaje se desdobla en 2 partes. Teórica y Práctica. La verdad es que no tiene mucho sentido hacerlo por separado porque cuando conducimos empleamos ambas facetas al mismo tiempo. Por tanto lo ideal sería aprender la teoría mientras practicamos ya que es cuando mejor estableceremos la conexión entre la teoría y su aplicación en la vida real. Dando por hecho que es imprescindible conocer las señales y las normas básicas de circulación, la parte clave es el aspecto práctico, manejarnos con el vehículo. Es decir, lo que vamos 
a hacer durante nuestra vida va a ser conducir un coche en multitud de situaciones. Nadie entendería que para aprender a conducir solo hiciésemos un examen teórico. Sin embargo, en la mayor parte de los casos en las que las empresas o las instituciones educativas tratan de enseñar algo a los alumnos, casi nunca los alumnos tienen la oportunidad de practicar, de «Hacer» eso que les queremos enseñar. Los cursos de Ventas, Inteligencia Emocional, Atención al Cliente, Gestión de Proyectos, Dirección de Reuniones y cualquier ejemplo que queramos poner describen situaciones, hablan de principios, teorías, definiciones pero no ponen al alumno en situación de Vender, Empatizar o Atender a un cliente. El alumno NUNCA vende ni atiende clientes. Increíble pero cierto, máxime cuando la actividad de los alumnos al finalizar el curso será precisamente esa. No obligan a pensar, a tomar decisiones, a equivocarse, a reaccionar. Se trata de razonamiento superfluo, superficial. Hagamos esta reflexión: ¿Cuánto tiempo pasa el alumno activamente, haciendo cosas durante el curso? ¿Y cuanto tiempo pasivamente leyendo, escuchando, mirando?

Los Expertos: Historias, Casos y ejemplos. Las personas pensamos en palabras y nos comunicamos básicamente hablando. Nuestra vida es una historia y cuando describimos situaciones, lo solemos hacer en forma de cuentos e historias y nos apoyamos en ejemplos para hacernos comprender mejor. Desde el principio de los tiempos, la tradición oral ha tenido una importancia capital y por tanto ha incorporado en sus relatos una enorme cantidad de información y conocimiento.

Una figura clave a la hora de diseñar cualquier contenido son los expertos, aquellas personas, dentro o fuera de la organización, que han conseguido dominar su área de actividad hasta ser reconocidos como los mejores. Debemos ser capaces de trabajar con ellos para entender cuál es el proceso que siguen, donde se cometen los errores mas habituales, cuál es la mejor manera de resolverlos, etc., y construir contenidos para que el resto de empleados puedan "vivir» esas mismas experiencias. Pero sobre todo, que en los momentos en los que los alumnos necesiten ayuda para avanzar, puedan tener a su alcance a esos expertos, grabados en video, online, para consultarles. No podemos desaprovechar oportunidades de aprender y por eso los expertos deben estar siempre disponibles. Mi padre era ese experto cuando tenía problemas para aparcar o cuando el coche salía dando tirones al arrancar y meter primera. Obviamente, el valor de la tecnología es el de proporcionarnos al alcance de la mano a todos esos expertos a los que posiblemente nunca podamos conocer. Hace cientos de años, la educación estaba reservada para unas elites. Sólo algunos tenían acceso a ella. Esos privilegiados tenían sus tutores particulares que les educaban en un entorno 1 to 1 en todo tipo de materias. La democracia trajo consigo la universalización de la educación y pasamos a un entorno de aprendizaje masificado 1 to X. En lugar de 1 profesor y 30, 50, 100 alumnos, la tecnología nos permite pasar a la situación contraria:10 profesores para 1 alumno. ¿Hay quien dé más? 
Disponer de la información relevante en el momento en que se necesita. Está muy relacionado con el aspecto de la motivación. Si no voy a utilizar lo que estoy aprendiendo hasta dentro de 10 meses, difícilmente lo voy a tener muy en cuenta. Cuanto más se aproxime el entorno de aprendizaje a la realidad en la que tenemos que el alumno desempeñe el trabajo, tanto más efectivo será. Y cuanto mas cercano sea a sus intereses mas fácil será que aprenda y quiera saber mas. Además, en la era de Internet lo lógico es que la gente aprenda cuando lo necesite y no cuando conviene realizar el curso o las aulas están libres o a los expertos les va bien.

Motivación: La motivación y la curiosidad son la energía para el aprendizaje. No hay nada que pueda superar la fuerza de una persona que está encandilada por un tema en particular. Cuántos compañeros hemos tenido en la escuela que sacaban malísimas notas pero lo sabían todo sobre deportes. Todos tenemos un enorme caudal de energía y creatividad del que desconocemos sus límites y que se desaprovecha porque nuestro sistema educativo y laboral lo reprime. Si alguna vez habéis visto cuantas personas hacen falta para reducir a un demente lo comprenderéis. El reto consiste en transformar a los alumnos de asistentes en participantes. Como indicaba al comienzo, de nada hubiera servido que alguien tratase de enseñarme a conducir cuando tenía 12 años. El alumno debe perseguir sus propios objetivos y solo aprendemos cuando nos hacemos una pregunta y vamos a buscar la respuesta y no cuando la respuesta nos viene sin que la hayamos pedido. Tenemos una magnífica oportunidad para ofrecer a los empleados instrumentos y herramientas para hacer mejor su trabajo Y la mayoría de personas agradecen esa posibilidad, a nadie le gusta la sensación de inseguridad y el temor a no hacerlo bien.

Los errores: Es muy importante practicar pero sobre todo es importante cometer errores. ¿Por qué? Porque cuando cometemos un error, se pone en marcha un mecanismo automático que busca la manera de resolver el problema, o bien por mí mismo o bien pidiendo ayuda a alguien. Y es en ese momento en el que estamos preparados para encontrar una solución o escuchar a alguien que nos ayude a encontrarla. Ese momento de aprendizaje es la clave y sólo se desata cuando las cosas no suceden como preveíamos. Por ello, la práctica perfecciona el aprendizaje y la reflexión lleva al aprendizaje profundo. El mejor ejemplo de esto son los niños: No saben que aprenden, no son conscientes y tienen objetivos (hablar para comunicarse, andar para explorar sitios, etc). Son auténticas máquinas de aprender: ¿ alguien ha visto un niño deprimido por sus errores o que ha decidido dejar de intentar aprender a andar? Están motivados y aprenden a base de cometer errores que los padres siempre entienden como imprescindibles.

El ordenador nos permite practicar tantas veces como sea necesario. Los ordenadores tienen una paciencia infinita con nosotros y sobre todo nuestros errores no tienen consecuencias porque constituyen entornos seguros de aprendiza- 
je. Y mientras en la vida real, las personas cometen errores accidentalmente, en el mundo virtual podemos provocar que los cometan. Y esta es una ventaja de la que podemos sacar un provecho incomparable y sino pensemos en los simuladores de vuelo. También permiten reproducir escenarios costosos o peligrosos con relativa comodidad.

El estudiante decide su propio ritmo y controla su proceso. Parece indiscutible que si estamos viviendo la era del «1 to 1 », resulte difícil entender que los alumnos tengan que estar el mismo día, en un mismo sitio, a la misma hora, en la misma página. Y que si un profesor explica algo, mientras un alumno se queda pensando en ello, aquel continúa avanzando. Las personas, aunque aprendemos todas igual (haciendo) tenemos diferentes estilos. Unos prefieren pasar directamente a la acción, otros prefieren investigar, otros solicitar consejo, otros ver cómo lo hace un experto. Por eso un buen contenido deberá tener en cuenta que hay que proporcionar diferentes vías para que todos esos estilos estén representados y el alumno pueda escoger su propio camino. Además no todos tenemos la misma capacidad para aprender, unos van más rápido que otros. Tenemos 5 sentidos y cuantos más de ellos impliquemos, más le facilitaremos la labor. Por tanto, el e-learning consiste también en dar al alumno la libertad para avanzar cuándo y cómo quiera.

El resultado de la tarea es el examen. ¿Tiene mucha importancia el hecho de que aprobase el examen teórico o lo que realmente cuenta es que sepa conducir? Tenemos una tendencia difícilmente controlable de medir el conocimiento sobre la base de exámenes y tests. Posiblemente porque resulta mucho más fácil que tratar de medir el desempeño. Pero la vida es mucho más que Verdadero o Falso. Tratemos de medir tareas reales y no lo simplifiquemos por muy cómodo que nos resulte. Si quiero enseñar a alguien a andar en bici y al día siguiente viene andando en bici, no me preocupa demasiado que sepa responder cuantos radios tiene la rueda o donde está el freno delantero.

Entretener. El aprendizaje debe ser divertido. Pensar puede ser divertido y aprender también. Aunque la tradición nos asocia la educación con entornos serios (todos con uniforme, en silencio o nos castigaban) la realidad es que los seres humanos nos involucramos con aquello que nos divierte, que nos entretiene. Lo llevamos en la sangre desde niños. Nos gusta jugar, nos gusta disfrutar y si ponemos un poco de creatividad, veremos que no es tan complicado aquello de «proponer una experiencia agradable de aprendizaje». Es más, va a resultar imprescindible. Vivimos una sociedad de estímulos constantes, de ocio, cine, televisión, videojuegos y los alumnos no van a entender ni aceptar contenidos aburridos, planos. Van a querer aprender y pasárselo bien mientras aprenden. Pero por muy maravilloso que sea el clima, por muy gratificante que sea la experiencia, si no está conectada directamente con lo que cada individuo enfrenta en el día a día de su trabajo, no lograremos que sea efectivo para el fin que se le supone: Que sean capaces de hacer mejor sus tareas. 
Las emociones. Los seres humanos recordamos las experiencias que nos han dejado huella en nuestra vida. La primera novia, un accidente, el fallecimiento de un familiar, el 11 de septiembre. Como decíamos, memoria y emoción van íntimamente ligadas. Cuando vamos al cine, no sólo lo hacemos porque nos divertimos sino que nos hace soñar, emocionarnos, a veces reflexionar, vivir historias, identificarnos con personajes, odiarlos, defenderlos, llorar, reír. Y sin embargo sabemos que es sólo una película. Si somos capaces de provocar ese tipo de reacciones en un alumno, reforzaremos enormemente el aprendizaje. Debemos esforzarnos por provocar situaciones memorables, intensas, perdurables, donde el alumno se olvide de que esta en una simulación virtual y viva las sensaciones que vive en la vida real. Y se puede hacer, ya lo creo que se puede.

El aprendizaje es individual. Aunque las personas vivimos, aprendemos y trabajamos en grupo, el aprendizaje real es individual. Lo que yo sé HACER, me lo llevo conmigo allá donde vaya. Los grupos fomentan la relación social y refuerzan el aprendizaje pero el proceso es individual. El e-learning permite las diferencias entre personas. Aprendo de otros y con otros pero aprendo YO. O YO sé conducir o no lo sé. Por eso el rol del profesor será primero Aprender a Enseñar para luego Enseñar a Aprender (y no tanto ser el mejor experto en su materia) y el del alumno cada vez más aprender a aprender.

\section{¿POR QUÉ EL E-LEARNING ESTÁ FRACASANDO?}

Porque hay cosas que hoy en día los ordenadores no pueden reproducir como el mundo real. Para aprender a hablar en público, no hay mas remedio que hablar en publico.

Porque la manera en que aprenden las personas no tiene nada que ver con la forma en que tratamos de enseñarles. Estudiar no tiene sentido, aprender si que lo tiene. No es natural pasarse horas sentado leyendo o escuchando cuando nos pasamos el día haciendo cosas, activos, en continuo movimiento.

Y porque parte de los responsables de e-learning en las empresas son los antiguos responsables de formación y estamos en la situación que asemejaría a poner en manos de Correos y Telégrafos el hacerse cargo del e-mail.

\section{LOS ERRORES MÁS HABITUALES AL DISEÑAR CONTENIDOS}

Digitalizar los contenidos en papel actuales. Por el mero hecho de poner información o contenidos en una web no significa que se vayan a aprender. Internet es una gran biblioteca pero eso no equivale a pensar que hemos reunido todo el conocimiento de la tierra en una sola y gigante base 
de datos. Si seguimos colgando en la red los mismos manuales que utilizamos en las aulas, solo estamos empeorando el modelo por mucho que lo queramos disfrazar con foros, tutores y herramientas colaborativas.

D Creer que escuchar, leer y memorizar es aprender.

Dreer que escoger una respuesta equivale a practicar.

D Creer que escoger la respuesta correcta es un buen examen de aptitud.

D Dar la respuesta correcta cuando te equivocas.

D Creer que describir una situación sustituye estar y vivir esa situación.

D Olvidar que aprender y divertirse no son conceptos opuestos.

\section{TÚ PRACTICAS, Y CUANDO TENGAS PROBLEMAS TE AYUDAMOS}

Para esto es para lo que nos sirven las tecnologías. El 1 a 1 del e-learning cambia el modelo: Los ordenadores no se aburren, eliminan el miedo al fracaso y al ridículo, permiten experimentar, simular situaciones reales y diferentes estilos de aprendizaje.

El proceso para el alumno es el siguiente:

1. Se sitúa en un Escenario: Situación real (física o virtual).

2. Le planteamos unos Objetivos realistas que debe alcanzar

3. Se empieza a hacer preguntas para lograr alcanzar los objetivos y le surgen dudas:

4. Aquí entramos ofreciendo soporte: expertos, historias, teoría, etc.

Ahora háganse esta pregunta: ¿Cuántos cursos conocen donde se conjuguen todos estos elementos? ¿Cuándo han visto un curso tan bien diseñado que les entrasen unas ganas irresistibles de hacerlo?. Además, los profesionales no necesitan cursos, lo que necesitan son soluciones a problemas. Llamar e-learning a lo que se hace a día de hoy me parece un poco atrevido. Hay nombres más adecuados como e-reading o e-training. Existen contadísimas personas que puedan ser consideradas expertas en este campo que hace muy pocos años era un completo desconocido. Conocemos muy pocas experiencias de éxito y en cambio existe bastante confusión. Un buen profesional no es sinónimo de buen formador. Y un buen formador presencial tampoco es sinónimo de buen formador online.

Les brindo la ocasión de que hagan el siguiente experimento: Acudan a cualquiera de los múltiples seminarios, conferencias, jornadas sobre e-learning (los hay por docenas) y fíjense a ver si son capaces de encontrar en alguna de ellas algún ejemplo real de algún curso real hecho para algún cliente real que de verdad 
Contenidos en e-learning: El Rey sin corona (por ahora)

les impacte, les resulte una experiencia interesante sobre cómo aplicar las tecnologías para que las personas aprendan mejor. Créanme, les van a sobrar dedos de una mano. ¿Por qué? Muy sencillo, porque jamás se mira el mundo a través de los ojos del alumno y porque todavía no tenemos experiencia en este campo. No podemos construir cursos para e-learning sin antes comprender cómo aprenden las personas y sin entender que estamos hablando de un medio nuevo como es Internet. Estamos empleando las nuevas tecnologías (Internet) con la mentalidad antigua (editorial) lo cual es en cierta manera natural. Los comienzos de cine tienen muchas similitudes con esta situación. Las primeras películas de los hermanos Lumiere trataban de filmar obras de teatro o escenas de la vida real como «Obreros a la salida de una fábrica». Tuvieron que pasar algunos años hasta que el cine desarrollase su propio lenguaje (guiones, exteriores, sonido, efectos especiales, montaje) para llegar a ser lo que hoy conocemos. Así que tenemos que ser conscientes de que por regla general, nos encontramos en la primera generación de contenidos de e-learning, que siguen un esquema similar al de un libro de texto aunque aprovechando las mejoras que permite la digitalización como incorporación de la imagen, animación, sonido y la capacidad de poner ejercicios online al alumno. Estos contenidos son lineales y secuenciales y utilizan el examen como herramienta de evaluación.

Sin embargo, si hablamos de contenidos a día de hoy, seguimos hablando del hermano pobre del e-learning. La mayor parte de las inversiones económicas se están realizando en tecnología (LMS, comunicaciones, hardware) que no deja de ser un medio y nunca un fin (condición necesaria, sí, pero no suficiente). Esto nos conduce a poner un énfasis desmedido en la distribución y por tanto en el ahorro de costes sin preocuparse apenas por la calidad. Como resultado, las primeras experiencias de los alumnos con un curso vía e-learning resultan aburridas y decepcionantes generando una importante tasa de abandonos. No perdamos de vista que las tecnologías que empleemos para el aprendizaje son el soporte, el vehículo que nos permite un acceso más rápido, más sencillo, más completo. Pero la clave está en los contenidos. La tecnología es a los contenidos lo que el envoltorio al caramelo. Ambos son imprescindibles pero lo que nuestros alumnos necesitan son los contenidos, el motivo por el que los formamos no es la tecnología, lo que van a emplear para trabajar son los contenidos. El aprendizaje dejará de ser un anexo, un paréntesis en el trabajo para integrarse y formar parte como un elemento mas.

Hace tiempo leí estas dos asombrosas estadísticas: Sólo del 10 al 20\% de lo aprendido se transfiere al puesto de trabajo. A partir del año 2002, por cada euro que se gaste en tecnología, se gastarán cinco en contenidos.

La clave del e-learning radica en que es la ÚNICA manera de proporcionar información y conocimientos actualizados a los trabajadores (las armas claves para competir) en un entorno donde es el rápido quien vence al lento y no el gran- 
de al pequeño. Los métodos tradicionales de formación simplemente no van a poder mantener el ritmo. Todo esto es especialmente cierto en grandes organizaciones con alto número de personas a formar y amplia variedad de productos $\mathrm{y}$ servicios. Por tanto las empresas no quieren el e-learning, necesitan el e-learning. Y tenemos que empezar a pensar en los contenidos de segunda generación. Aquellos que están concebidos para que el alumno aprenda algo a través de la práctica de ese algo, que se basan en la idea del simulador, que son totalmente activos, en los cuales no hay teoría y la evaluación se realiza en la medida en que el alumno es capaz de completar una tarea.

Para finalizar, parece una obviedad hacer hincapié en que nos hallamos ante una magnifica oportunidad. El mercado de la educación va a ser uno de más importantes en los próximos años (ya es el segundo en la economía estadounidense). Las empresas saben que la única ventaja competitiva sostenible es lo que saben hacer sus empleados. Y las personas son conscientes de que aprender es ya crucial para desarrollar su carrera profesional. La demanda no cesa de crecer continuamente.

Como he venido sosteniendo, no hay nada mejor que el aprendiz que aprende junto al maestro y tiene la oportunidad de mirar por encima de su hombro para ver cómo hace las cosas y recibir su consejo cada vez que comete un error. Y esto, que hasta hace poco tiempo resultaba prohibitivo, la tecnología ya nos lo permite de manera que las personas pueden aprender de forma natural, como siempre lo han hecho. No desaprovechemos la ocasión. Hoy cuando los alumnos se asoman a un campus virtual, o bien encuentran muy pocos contenidos o los que hay no les ilusionan. Como cuando vamos al cine con ánimo de disfrutar un rato, una buena película nos engancha, una mala nos aburre.

Pero mañana las cosas no serán así. La calidad de los contenidos será la clave por la que las personas se decantarán por una u otra oferta. La tecnología será transparente (al igual que lo es hoy en el caso del cine y la televisión). Y quienes empiecen a diseñar y construir contenidos teniendo en cuenta estos y otros aspectos, tendrán más posibilidades de triunfar en esta aún incipiente industria del e-learning.

Esta es la pregunta que nos deberíamos hacer siempre que vayamos a diseñar contenidos: ¿Como podemos convertir una experiencia de recepción pasiva de información en una experiencia activa de construcción de conocimiento?.

Los contenidos reinarán y aunque todavía están sin corona no será por mucho tiempo. 
Contenidos en e-learning: El Rey sin corona (por ahora)

\section{PERFIL ACADÉMICO Y PROFESIONAL DEL AUTOR}

Javier Martínez Aldanondo es Licenciado en Derecho por la Universidad del País Vasco, Máster en Internet Management por el Institut Català de Tecnología y Máster en Comercio Exterior por la Cámara de Comercio de Guipúzcoa. Es Director de Proyectos e-learning de Talentus Servicios Innovadores en Aprendizaje (www.talentus.cl) empresa propiedad de Gecsa (La Caixa, Telefónica, UOC) y del Intec (Instituto Tecnológico de Chile). Asimismo fue socio fundador y Consultor del area de e-learning de Neos Conocimiento y Aprendizaje (www.neostraining.com) y socio fundador y Director de Marketing de Ameca Servicios Corporativos.

Dirección electrónica: jmartinez@talentus.cl 